\title{
A QUALIDADE NA EDUCAÇÃO A DISTÂNCIA: UMA PESQUISA BIBLIOMÉTRICA DA PRODUÇÃO CIENTÍFICA
}

\author{
RIO DE JANEIRO/RJ MAIO/2018 \\ JOEL PEIXOTO FILHO - IFSEMG - joel.peixoto@ifsudestemg.edu.br \\ CARMEN IRENE CORREIA DE OLIVEIRA - UNIRIO - irenecor2004@gmail.com \\ Tipo: Investigação Científica (IC) \\ Natureza: Descrição de Projeto em Andamento \\ Categoria: Estratégias e Políticas \\ Setor Educacional: EDUCAÇÃO SUPERIOR
}

\begin{abstract}
RESUMO
A preocupação sobre a "qualidade" sempre foi um tema central no âmbito da educação a distância no Brasil, sobretudo, motivada em função de questionamentos por uma parcela da sociedade ou por parte do próprio Estado, através de seus órgãos reguladores. Neste cenário, cresce a necessidade por parte das Instituições de Ensino que atuam no setor de EaD, em aprimorar seus controles internos, visando a busca pela melhoria contínua da qualidade de seus cursos. Não menos importante é a ampliação da participação do meio acadêmico na busca pelo desenvolvimento de novas metodologias que possam ampliar e contribuir para a melhor compreensão em torno do tema "qualidade" na educação a distância. Assim, o objetivo deste trabalho é apresentar os resultados da "primeira etapa" de uma pesquisa, em nível de doutorado, sobre a qualidade na EaD. Nesta etapa inicial, serão expostos os dados referentes à aplicação da metodologia "Estudo Bibliométrico" sobre a produção científica disponível nas bases científica "Scopus Elsevier", acessada através do Portal de Periódicos da Capes, e nos "Anais do CIAED", no período compreendido entre 2007 e 2017. Os resultados levantados e analisados mostraram-se eficientes e irão contribuir, de forma significativa, para a busca de trabalhos já consolidados sobre o tema "qualidade" considerados essenciais para o desenvolvimento das próximas etapas desta pesquisa.
\end{abstract}

Palavras-chave: Qualidade; Educação a Distância; EaD; Critérios de Qualidade

\section{AGRADECIMENTOS}

OS AUTORES AGRADECEM À FUNDAÇÃO DE AMPARO À PESQUISA DE MINAS GERAIS FAPEMIG, PELO APOIO FINANCEIRO CONCEDIDO PARA A PARTICIPAÇÃO NO EVENTO. 


\section{INTRODUÇÃO}

A qualidade é um fator intermediador em diversas áreas da sociedade uma vez que impõe padrões e determina as relações de consumo para produtos e serviços. No caso dos padrões, eles são mais explícitos em se tratando de produtos físicos, pois a partir da $2^{a}$ guerra mundial, conforme Faria (2016) as indústrias e os governos, principalmente no Japão a partir da década de 1950, estabeleceram uma série de normas que propiciaram a produção padronizada visando à diminuição de produtos defeituosos e o aumento da durabilidade, além da criação dos inspetores de qualidade, que logo foram substituídos pelas técnicas estatísticas de controle de qualidade.

Se por um lado a qualidade pode ser mensurada mais facilmente em produtos devido às suas características físicas (dimensão, estética, design, etc) e aos diversos padrões estabelecidos pelo mercado (como a durabilidade), o mesmo não acontece com os serviços. Devido a sua natureza intangível e menor durabilidade no consumo, existe um maior grau de dificuldade por parte dos consumidores em estabelecer padrões perceptivos sobre a qualidade. Isso levou diversos persquisadores a buscar 0 desenvolvimento de técnicas de medição para serviços, sendo Grönroos um dos pioneiros nesse sentido (MIGUEL \& SALOMI, 2004).

Apesar disso, a qualidade ainda constitui um importante indicador para o setor de serviços, incluindo-se as organizações que ofertam ensino em seus diversos níveis e/ou modalidades. No caso específico da EaD, temos uma modalidade de ensino que vem se destacando nos últimos anos pelo seu crescimento em número de matrículas (Figura 1) quando comparado com o ensino presencial (INEP, 2017) e, principalmente, pelo seu potencial em expandir o atendimento às regiões e às camadas sociais historicamente marginalizadas pelo ensino presencial (MACEDO et al., 2014).

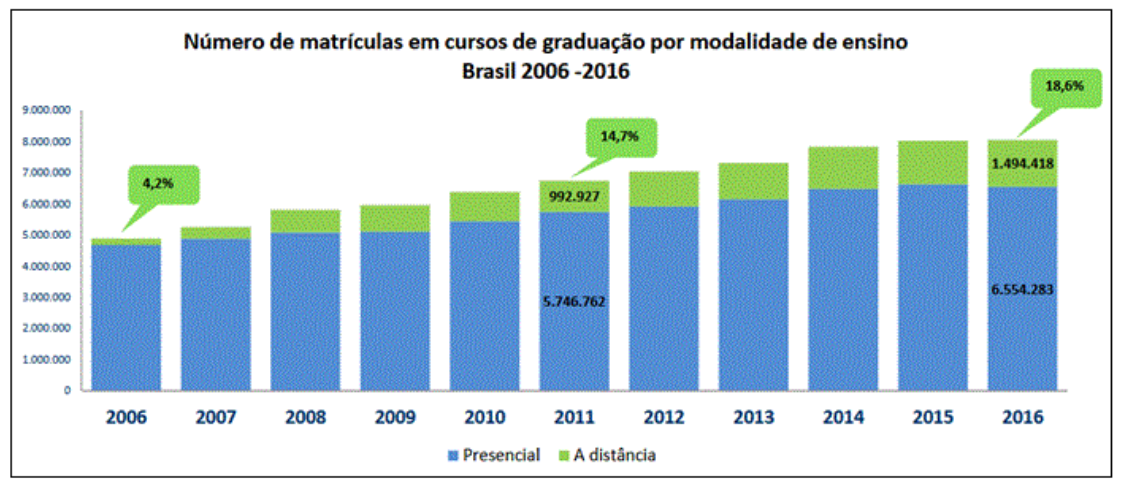

Figura 1 - Matrículas em cursos de graduação. Fonte: INEP (2017)

O crescimento substancial do número de matrículas na EaD foi conquistado nos últimos anos, sobretudo, pela ampliação da oferta de cursos pelo setor privado e em menor 
escala, pelas políticas governamentais como a criação da Universidade Aberta do Brasil em 2005 e a Rede e-Tec Brasil em 2007. No entanto, essa ampliação acelerada da oferta trouxe certa desconfiança e crítica por parte de uma parcela da sociedade. Como afirma Luck (2008), a modalidade EaD precariza o trabalho do professor, além de ser fortemente calcada em interesses econômicos.

Para que este cenário de expansão da educação a distância se consolide, sem a ocorrência de retrocessos, é importante que as instituições de ensino, pesquisadores, gestores, ou seja, a comunidade acadêmica em geral, participe de forma proativa na ampliação da discussão em torno da qualidade na educação a distância no Brasil. Nos últimos anos, foram os órgãos ou setores governamentais (MEC, INEP, entre outros) que assumiram a dianteira em torno da discussão sobre o estabelecimento de critérios e padrões de qualidade para a EaD, como por exemplo a criação e as revisões dos "referenciais de qualidade". Mesmo sendo papel do Estado regulamentar a educação a distância no Brasil, há espaço para que os demais atores que compõem este processo, inclusive o corpo discente, contribuam para o fortalecimento desta importante discussão.

\section{OBJETIVO}

O objetivo deste estudo é apresentar os resultados da primeira etapa de uma pesquisa em andamento, em nível de doutorado, sobre o tema "qualidade" na EaD. Esta etapa inicial consiste na aplicação da metodologia "estudo bibliométrico" (metodologia oriunda das áreas de Biblioteconomia e Ciência da Informação), em uma das principais bases científicas em língua estrangeira, a Scopus Elsevier, e nos anais do Congresso Internacional ABED de Educação a Distância (CIAED), considerado uma referência no setor.

\section{REFERENCIAL TEÓRICO}

\subsection{OS REFERENCIAIS DE QUALIDADE DA EDUCAÇÃO SUPERIOR A DISTÂNCIA}

Foi somente após a publicação da LDB - Lei de Diretrizes e Bases da Educação (9.394/96), que surgiram os primeiros estudos e legislações que tratavam dos indicadores e/ou critérios de qualidade para a $\mathrm{EaD}$, destacando-se a pesquisa publicada em $1997^{1}$ e o decreto do Governo Federal de $1998^{2}$. A partir daí, surge a necessidade da criação de um documento balizador para a padronização de normas e ações voltadas à qualidade do ensino superior a distância no país, conhecido atualmente como "Referencias de Qualidade para a Educação Superior a Distância", cuja última versão é de 2007. A figura 2 a seguir, apresenta as principais etapas de criação e revisão deste 
importante documento.

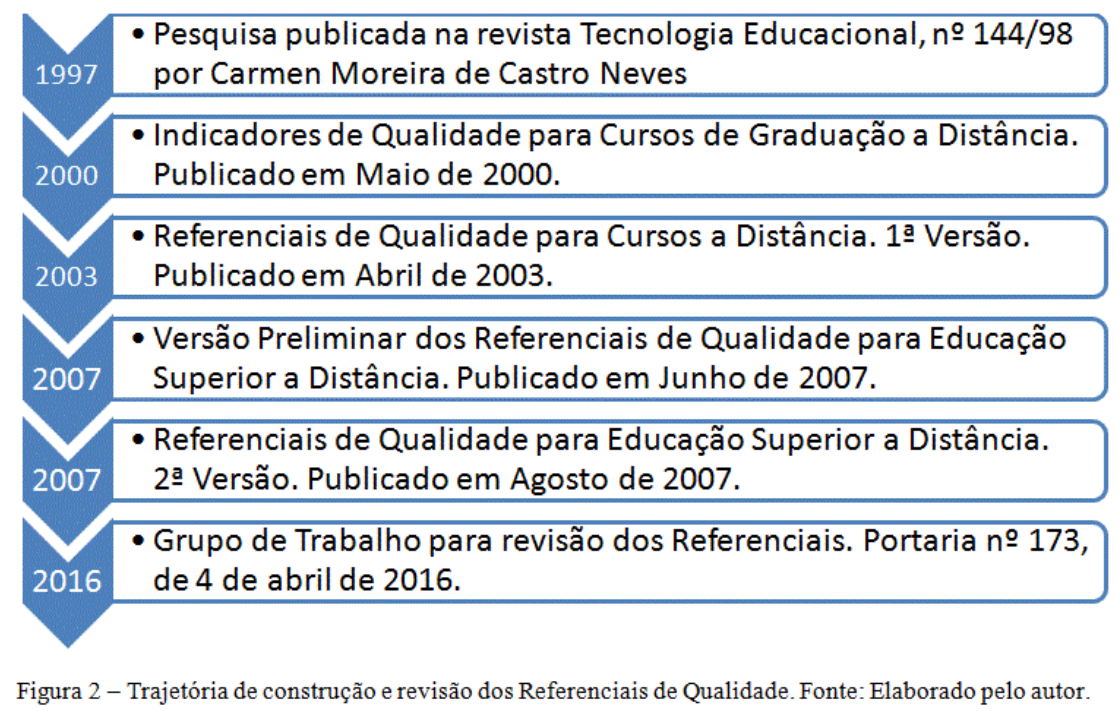

\subsection{ANÁLISE BIBLIOMÉTRICA}

A bibliometria é uma das mais importantes ferramentas utilizadas hoje pela comunidade acadêmica para a pesquisa de produções científicas sobre determinado assunto ou área. Tendo como foco este conjunto de informações, o pesquisador construirá uma base de dados confiável que dará suporte ao desenvolvimento de outros estudos, tornando-se um ponto de partida importante na geração de conhecimento (AMARAL, et al., 2004). Já para Xavier et al. (2012), a bibliometria apresenta-se como um conjunto de métodos matemáticos e estatísticos utilizados para investigar e quantificar os processos de comunicação escrita. Alguns parâmetros passíveis de estudo são autores, palavraschave, citações, periódicos e publicações, ano de publicação, origem dos trabalhos, áreas do conhecimento entre outros.

O conjunto de informações levantadas com o auxílio da bibliometria são decisivos para o início de diversos estudos, no entanto, a escolha da melhor metodologia ou da melhor abordagem a ser utilizada é essencial para que os resultados alcançados possam ser satisfatórios. Para Alvarado (1984) a bibliometria envolve, entre outras abordagens, três leis básicas: 1) Lei de Bradford - descreve a distribuição da literatura periódica numa área específica; 2) Lei de Lotka - descreve a produtividade dos autores; 3) Lei de Zipf descreve a frequência no uso de palavras num determinado texto.

\section{ASPECTOS METODOLÓGICOS}

Com o intuito de conhecer a relevância da pesquisa em torno do tema "qualidade", no 
âmbito da educação a distância, no Brasil e no exterior, o presente estudo foi dividido em duas etapas, considerando cada uma das bases acessadas. Os aspectos metodológicos aplicados ao desenvolvimento do estudo são os elencados por Costa (2010): 5.1 - Definição da amostra da pesquisa; 5.2 - Pesquisa na amostra, com as palavras-chave; 5.3 - Identificação dos periódicos com maior número de artigos publicados sobre o tema; 5.4 - Identificação dos autores com maior número de publicações; 5.5 - Levantamento da cronologia da produção, identificando "ciclos" de maior produção.

No caso dos artigos disponíveis na base de dados Scopus Elsevier, foi realizado um levantamento compreendendo os artigos publicados na área de ciências sociais no período delimitado entre o ano de 2007 (data de publicação da última versão dos referenciais) até o ano de 2017. O acesso à referida base foi realizado através do Portal de Periódicos da Capes, entre os dias 01 e 10 de março de 2018.

No caso da produção científica brasileira, foram pesquisados os anais do CIAED, no período compreendido entre 2007 (data de publicação da última versão dos referenciais) a 2017. A escolha pela realização da pesquisa bibliométrica, apenas no banco de dados citado, se deu pela importância deste evento no cenário nacional e internacional, em se tratando da discussão de temas e na publicação de trabalhos científicos relacionados à Educação a Distância.

\section{RESULTADOS}

\subsection{Definição da amostra da pesquisa}

A amostra utilizada neste estudo corresponde aos artigos disponíveis na base científica Scopus Elsevier e nos anais do CIAED.

\subsection{Pesquisa na amostra com as palavras-chave}

Para realizar a pesquisa na amostra indicada, foram selecionadas quatro palavraschave, sendo duas no idioma português e duas no idioma inglês, conforme tabela 1, que resultaram em 96 registros na base Scopus e de 76 registros nos anais do CIAED.

Tabela 1 - Registros dos Artigos Encontrados

\begin{tabular}{ccc} 
Palavras-chave & Base Scopus & Anais Ciaed \\
\hline "Quality" and "Distance Learning" & 96 & -- \\
"Qualidade" ou "Critérios de Qualidade" & -- & 76 \\
\hline \multicolumn{2}{c}{ Fonte: Elaborado pelo autor }
\end{tabular}




\subsection{Identificação dos periódicos com maior número de artigos publicados sobre o tema}

$\mathrm{Na}$ tabela 2 estão expostos os periódicos que possuem o maior número de publicações sobre o tema "qualidade e educação a distância", com destaque para o "Turkish Online Journal on Distance Education" com 15 registros encontrados.

\begin{tabular}{lc}
\multicolumn{2}{c}{ Tabela 2 - Distribuição de Publicações por Periódico (SCOPUS) } \\
\hline \multicolumn{1}{c}{ Título do Periódico } & Publicações \\
\hline Turkish Online Journal on Distance Education & 15 \\
International Review of Research in Open and Distance Learning & 8 \\
Distance Education & 7 \\
Computers and Education & 4 \\
Quality Assurance In Education & 4 \\
\hline
\end{tabular}

Fonte: Elaborado pelo autor

Já a figura 3, por se tratar de dados referentes a artigos publicados em anais de congresso, optou-se nesta pesquisa por apresentá-los segundo a "classificação" adotada pelo evento, de acordo com o documento "Chamada de Trabalhos". Analisando as informações dos gráficos é possível observar as categorias com maior representatividade em se tratando de artigos sobre o tema "qualidade" .
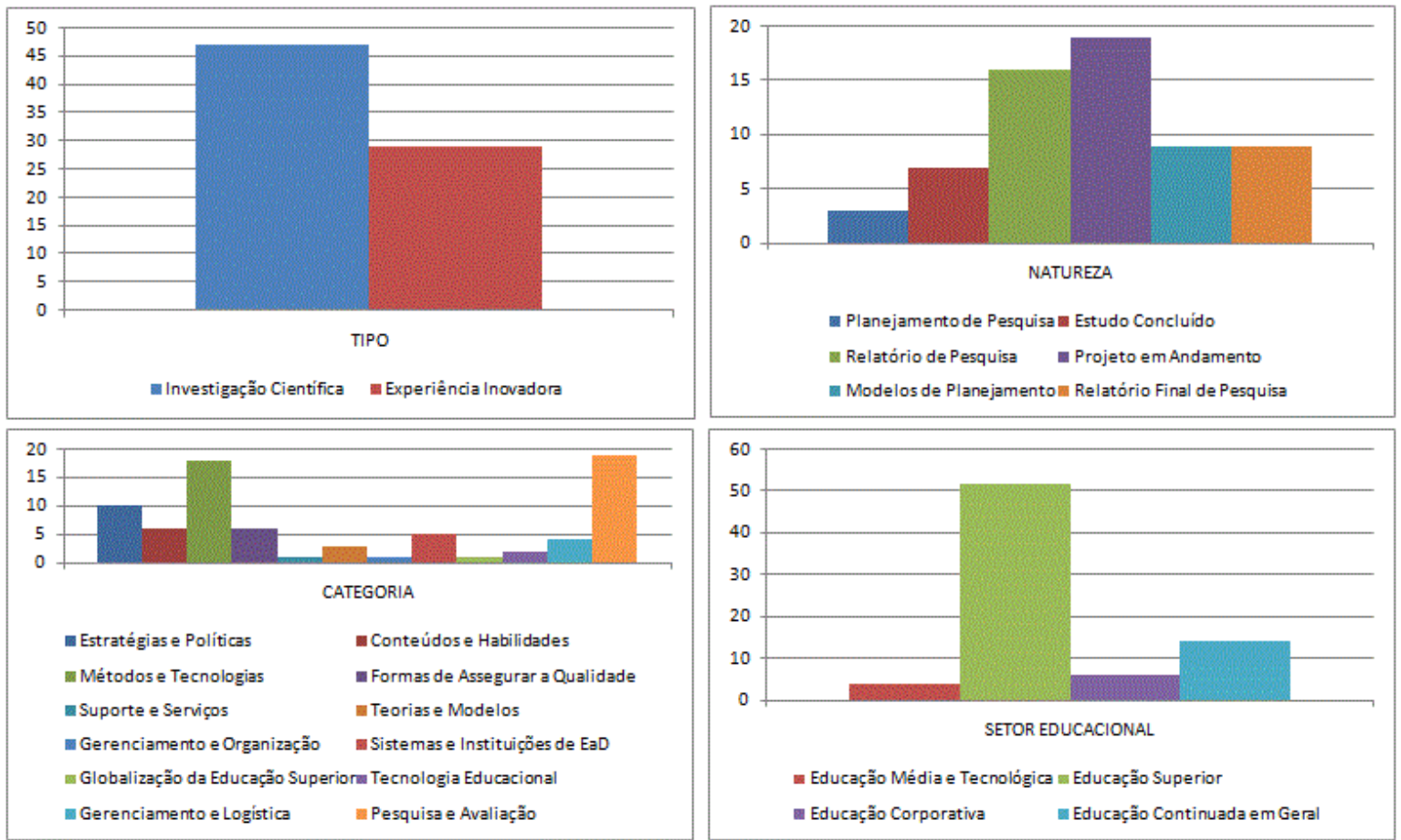

Figura 3 - Distribuição das publicações por categorias. Anais CIAED 2007-2017.

5.4 Levantamento da cronologia da produção, com identificação dos ciclos de produção 
Na figura 4, o gráfico 1 revela que EUA concentram o maior número de publicações (13 registros), seguido pelo Reino Unido (9 registros). O Brasil inclui-se entre os 10 países com maior número de trabalhos publicados sobre o tema "qualidade na educação a distância" (3 registros). No gráfico 2, estão representados os 10 autores com maior número de publicações sobre o tema em destaque.

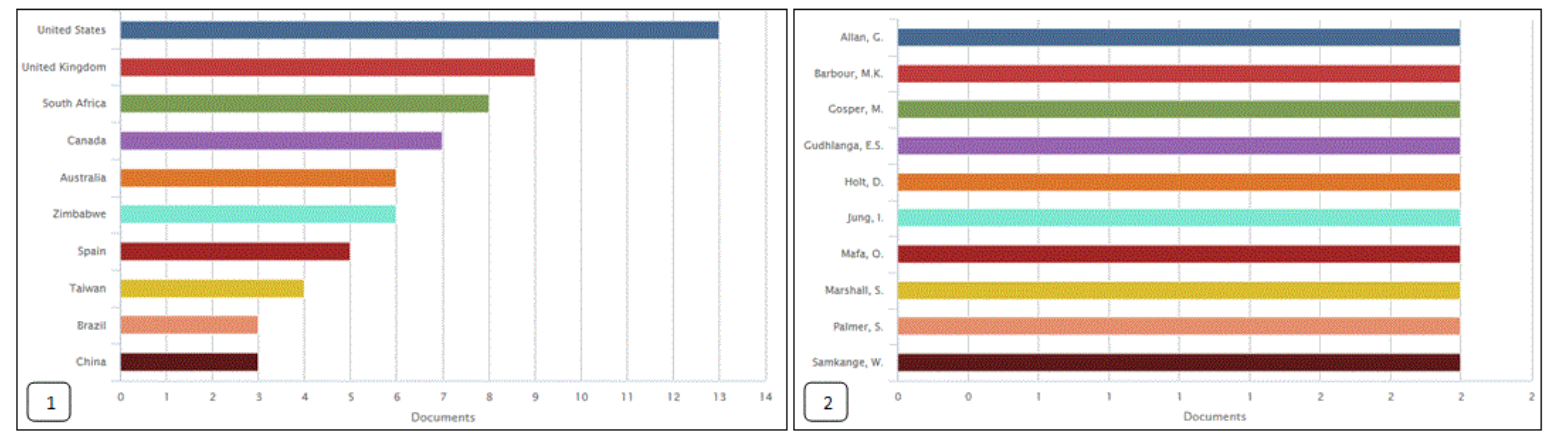

Figura 4 - Países e autores com maior número de trabalhos publicados. Fonte: SCOPUS ANALYSE (2018)

\subsection{Levantamento da cronologia, com identificação dos ciclos de produção}

$\mathrm{Na}$ figura 5 estão contemplados os dados referentes aos ciclos de maior publicação de artigos sobre o tema qualidade na educação a distância. No âmbito da base Scopus o ano de 2012 concentrou o maior número de trabalhos publicados (13 registros), seguido pelos anos de 2010 e 2011 com 11 registros cada. Já em relação aos artigos publicados em anais do CIAED, o ano de 2016 destacou-se frente aos demais períodos, com 24 registros.
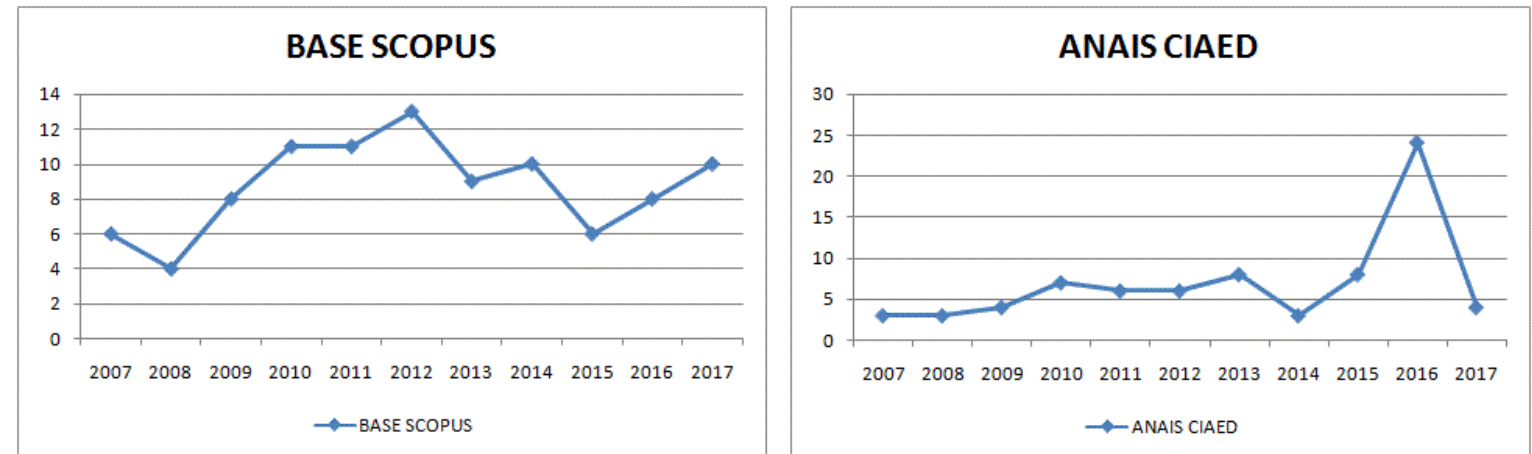

Figura 5 - Identificação dos ciclos de maior produção, 2007-2017. Fonte: Elaborado pelo autor.

\section{DISCUSSÃO DOS RESULTADOS}

A aplicação de métodos bibliométricos para levantamento da produção científica, é uma ferramenta essencial para subsidiar o desenvolvimento de pesquisas avançadas sobre um determinado assunto, como por exemplo, a elaboração de monografias, dissertações 
e teses. Seguindo esse mesmo direcionamento, o objetivo do presente estudo foi 0 levantamento de dados e informações que farão parte de uma pesquisa, em andamento, sobre o tema qualidade na educação a distância, no âmbito de uma tese de doutorado.

Os resultados levantados por meio da pesquisa na base científica Scopus (Figura 4 e 5), foram importantes para a construção de um perfil da produção científica em língua estrangeira, como por exemplo, os países com maior produção (EUA e Canadá), os periódicos de maior relevância (Turkish Online Journal of Distence Education e International Review of Research in Open and Distance Learning) e os períodos com maior ciclo de produção (2010 a 2012). No entanto, os resultados provenientes da pesquisa por autores revelaram a existência de uma dispersão significativa sobre o tema pesquisado, ou seja, os dados revelam que dos 96 artigos encontrados na referida base, 76 foram publicados por diferentes autores.

Se por um lado a pesquisa em bases científicas como a Scopus Elsevier é uma fonte de dados enriquecedora para o conhecimento de publicações em diversos países, por outro, a pesquisa em anais de eventos produz um resultado mais específico e concentrado sobre a produção científica de um país, em uma determinada área do conhecimento. Assim, a pesquisa nos anais do CIAED, considerado o maior evento do setor de EaD, agregou a esta pesquisa um importante conhecimento sobre a produção científica sobre o tema qualidade.

Aproveitando a já consolidada categorização adotada pelo referido evento para os trabalhos submetidos (Figura 3), foi possível traçar um perfil (Figura 6) contemplando todos os 76 artigos aprovados, seja para apresentação oral ou pôster. Já a tabulação dos dados por "ano de publicação" (Figura 5), revelou a existência de uma série praticamente constante na publicação de artigos com o tema "qualidade", entre os anos de 2007 e 2015, variando de 3 a 8 registros. Entretanto, na 22a edição do evento, realizado em 2016, houve um crescimento substancial na quantidade de artigos publicados, com 24 registros encontrados. Este resultado guarda uma relação direta com o tema do congresso para o ano de 2016 - "O contínuo desafio de aumentar a qualidade na EaD", evidenciando assim o grau de importância dos temas adotados pelos congressos para fomentar a pesquisa em uma determinada área. 


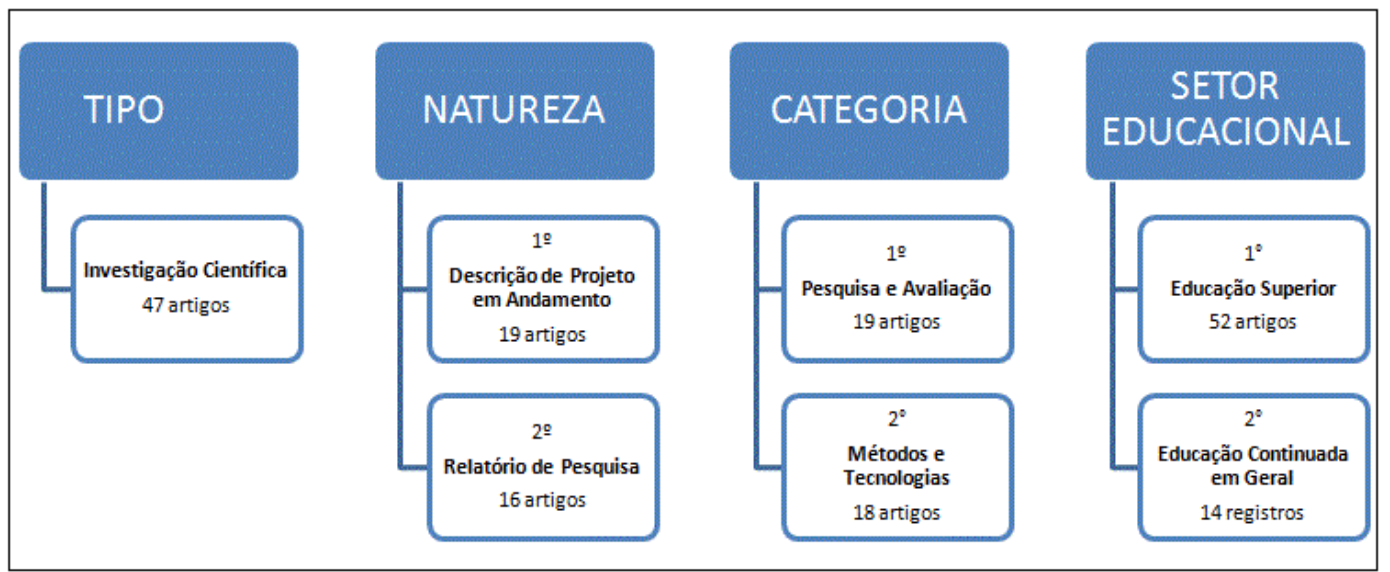

Figura 6 - Perfil dos artigos publicados. Anais CIAED, 2007-2017. Fonte: Elaborado pelo autor.

\section{CONSIDERAÇÕES FINAIS}

A aplicação da metodologia "pesquisa bibliométrica" mostrou-se eficiente para mapear o perfil da produção científica sobre o tema "qualidade" na educação a distância, tanto no Brasil como em outros países. A análise dos dados obtidos na base científica Scopus Elsevier e nos Anais do CIAED, como autores, periódicos, categorização e ciclos de produção, permitiram a busca dos artigos de maior relevância e a identificação de elementos que contribuirão para o desenvolvimento de um referencial teórico consistente para uma pesquisa em nível de doutorado.

\section{REFERÊNCIAS BIBLIOGRÁFICAS}

ALVARADO, R. U. A Bibliometria no Brasil. Ciência da Informação. Brasília, v.13, n.2, 1984.

AMARAL, R. M. et al. Uma visão da produção científica nos Anais do Encontro Nacional de Engenharia de Produção através da Bibliometria. XXIV Encontro Nacional de Engenharia de Produção. Florianópolis, 2004.

ASSOCIAÇÃO BRASILEIRA DE EDUCAÇÃO A DISTÂNCIA - ABED. ANAIS do Congresso Internacional ABED de Educação a Distânca, 2007 - 2017. Disponível em: < http://www.abed.org.br/site/pt/universo_ead/eventos_ead/>. Acesso em: 16 mar. 2018.

BRASIL. MEC. Ministério da Educação. Referenciais de Qualidade para Cursos a Distância. 2003. Disponível em: < http://portal.mec.gov.br/seed/arquivos/pdf/ReferenciaisdeEAD.pdf>. Acesso em: 15 mar. 2018. 
COSTA, Helder Gomes. Modelo para Webbliomining: proposta e caso de aplicação.

Revista da FAE, v. 13, n. 1, p. 115-126, 2010.

FARIA, C. História da Qualidade. InfoEscola, São Paulo,(2016) . Disponível em: Acesso em: 02 mar. 2018.

INSTITUTO NACIONAL DE ESTUDO E PESQUISAS EDUCACIONAIS ANÍSIO TEIXEIRA. Censo da Educação Superior 2016. Brasília, DF: INEP, 2017.

LÜCK, Esther Hermes. Educação a distância: contrapondo críticas, tecendo argumentos. Educação, v. 31, n. 3, 2008.

MACEDO, Andrea Cavalcanti; SANTOS, Marizete Silva; DE LIMA ALBUQUERQUE, José. A inclusão social da Universidade Aberta do Brasil. SIED: EnPED-Simpósio Internacional de Educação a Distância e Encontro de Pesquisadores em Educação a Distância, 2014.

MIGUEL, P. A. C.; SALOMI, G. E. Uma Revisão dos Modelos para Medição da Qualidade em Serviços. Revista Produção. v.14, n.1, 12-30, 2004.

SCOPUS. Base de Dados. Disponível em: < http://www.periodicos.capes.gov.br/>. Acesso em: 10 mar. 2018.

XAVIER, B. M. et al. Mineração de texto e suas aplicações na literatura cientifica-Estudo bibliométrico. Exatas \& Engenharia, v. 2, n. 04, 13-25, 2012.

[1] § 5o artigo 2o da Lei 2.494 de 10 de fevereiro de 1998.

[2] Os estudos considerados precursores para o desenvolvimento desse importante documento iniciaram-se em 1997 através de uma pesquisa publicada na revista Tecnologia Educacional $n^{\circ}$ 144/98 (BRASIL, 2003), pela pesquisadora Carmen Moreira de Castro Neves, que durante a publicação da primeira versão dos referenciais, ocupava a função de Diretora de Política de Educação a Distância. 